\title{
WestVirginiaUniversity
}

THE RESEARCH REPOSITORY @ WVU

Faculty Scholarship

2019

\section{Advertising Education at a Crossroad}

SANG Y. LEE

sang.lee@mail.wvu.edu

Follow this and additional works at: https://researchrepository.wvu.edu/faculty_publications

Part of the Mass Communication Commons

\section{Digital Commons Citation}

LEE, SANG Y., "Advertising Education at a Crossroad" (2019). Faculty Scholarship. 1173.

https://researchrepository.wvu.edu/faculty_publications/1173

This Article is brought to you for free and open access by The Research Repository @ WVU. It has been accepted for inclusion in Faculty Scholarship by an authorized administrator of The Research Repository @ WVU. For more information, please contact ian.harmon@mail.wvu.edu. 


\section{Advertising Education at a Crossroad}

Journal of Advertising Education $0(0)$ I-9

(C) The Author(s) 2019

Article reuse guidelines: sagepub.com/journals-permissions DOI: I0.I I77/I0980482/9867448 journals.sagepub.com/home/adv

@SAGE

\title{
Sang Yeal Lee'
}

\begin{abstract}
The changes in the advertising industry are rapid and dizzying. The advertising industry is going through structural change and advertising education faces a daunting challenge in keeping up with the real world. Advertising educators must recognize the urgency of revising the curriculum to address this challenge. If not, while the industry transitions into a different chapter, advertising education will be left behind. This article discusses major changes in the advertising industry, and calls for thought leadership to bridge the gap between academia and the industry and to initiate proactive changes in advertising education.
\end{abstract}

\section{Keywords}

curriculum development, digital gap, advertising thought leadership

The advertising industry has been going through major changes for the last decade or so. The changes in the industry are rather dramatic and even industry professionals lament advertising's identity crisis (Rubel, 2016; Stanol, 2018). For instances, the rise of consultancies and the resurgence of in-house agencies have disrupted the century-old advertising agency model; digital technologies have blurred existing advertising media boundaries; changes in consumer behaviors have altered buying habits and diminished the value of branding. These are not

\footnotetext{
'West Virginia University, USA

Corresponding Author:

Sang Yeal Lee, PhD, Associate Professor, Reed College of Media, 313 Martin Hall, West Virginia University, Morgantown, WV 26505-6010, USA.

Email: sang.lee@mail.wvu.edu
} 
emerging trends anymore. They have already impacted the advertising industry. In fact, each trend alone could be significant enough to rattle the entire advertising industry, but they are impacting the industry simultaneously.

While these changes have been going on for a decade, advertising education has largely been left behind. Advertising educators are now facing daunting challenges and trying to grapple with the nature of these changes. Some of these changes are beyond the traditional boundaries of advertising education and demand an urgent revision in advertising curriculum. Moreover, it's not just the advertising curriculum that needs updating; advertising faculty must also be informed about these changes to develop effective teaching strategies. The reality is that many developments in the advertising industry are unfamiliar to members of the advertising education community, and faculty members' efforts to learn these changes at individual level often face practical limitations.

According to Department of Labor statistics, the number of jobs in media and advertising has declined despite the economic expansion over the last several years (Thompson, 2018). This is not because the number of jobs is declining per se, but the developments in the advertising industry demand new and different talents. The advertising industry is seeking professionals with different sets of knowledge and skills rather than the traditional Mad Men. These days, it's not unusual for advertisers and agencies to hire professionals with nontraditional qualifications such as data scientists, data engineers, analytics managers, customer engagement analysts, digital creative directors, and experience designers, to name only a few. These job titles have mostly been added to agency job rosters over the last decade and are largely unfamiliar to advertising faculty and students. Given the mission of higher education, it is certainly true that colleges and universities have a responsibility to educate future citizens and leaders of society via a strong general education curriculum. However, it is equally important to educate advertising students with the conceptual knowledge and skills that the industry requires. Advertising education is at a crossroad in terms of educating future advertising professionals whose qualifications must meet the industry demands while keeping faith with a general education curriculum.

This article has several purposes. First, it discusses major changes that have impacted the structure of the advertising industry as well as the gap between academia and the industry. Second, it proposes possible pedagogical directions in advertising education that might narrow the gap. Third, the article calls for thought leadership to meet the challenges that advertising education is facing.

\section{Structural Shift in the Industry and Advertising Education}

\section{Rise of Consultancies and Resurgence of In-House Agency Models}

One major trend in the advertising industry is the rise of consultancies. Consultancies have advanced in the advertising business over the last decade, 
and in 2014, four consultancies (i.e., Accenture Interactive, PwC Digital Services, IBM iX, and Deloitte Digital) were listed among the world's 10 largest agency companies in the world (Schultz, n.d.). Consultancies bring a business model to the industry that is different from the traditional advertising agency model (see Bennin \& Kapoor, 2017). For example, some of the functions that consultancies provide, such as strategic branding capability or integrated strategic and data analytics solutions, have been weak spots or ignored areas by traditional agencies. By streamlining and integrating vertical and horizontal marketing and advertising functions, consultancies can work more closely with clients and function as a strategic partner rather than a vendor. Advertisers have been buying into the idea of consultancies and there is no reason to suspect that the trend will not continue in the future. The rise of the consultancies could be the direct result of the agency fragmentation and specialization that has been going on for decades under the umbrella of the holding company system in pursuit of efficiency.

Another noticeable structural change is the resurgence of in-house agencies. A 2018 industry survey suggested that $64 \%$ of corporate America have in-house agencies (Burns, 2018), although the services in-house agencies provide vary. The in-house agency model was once considered to be inefficient (Silk \& Stiglin, 2015), but it has rapidly gained popularity in recent years. The business model of in-house agencies is different from external agencies, and marketers believe in-house agencies provide advantages over traditional agencies in terms of cost savings, speed of work, and confidentiality of internal customer data (Bruell, 2018).

Both consultancies and in-house agencies have disrupted the existing agency ecosystem and these trends are expected to continue. Therefore, to reflect these changes, advertising curriculum must cover, for instances, in-depth knowledge of marketing including integrated branding, and management of technologies including data management, digital targeting, and data input in the creative process. However, the current advertising curriculum is not equipped to effectively teach these functions.

\section{The Digital Gap Between Academia and the Industry}

The digital gap between advertising education and the industry is clear. Digitalization in media and the advertising process has been going on for years in the industry. For example, programmatic buying has completely transformed the way digital media inventories are traded. While traditional media advocates may find comfort in the statistics and argue that traditional media still takes a lion's share in media expenditures, even legacy media inventories such as addressable television are increasingly purchased through programmatic buying (Bennett, 2018; Bruell, 2015). Further, the digital media market overcame the television market as of 2016 (Slefo, 2017) and the three technology-based 
companies - Google, Facebook, and Amazon - account for the majority of the digital media market (Soper, 2018). Moreover, as the advertising process increasingly incorporates digital technologies, ad fraud and ad blocking pose challenges, demanding more transparency in the advertising process from marketers (Stewart, 2018).

As the use of digital technologies such as AI and machine learning becomes more common in advertising and marketing processes, the accuracy of algorithm-based targeting will continue to increase in the coming years (Anonymous, 2018; Stephen, 2017; Yasmeen, 2017). Software companies such as IBM, Adobe, and Oracle have already blurred the boundary between advertising and marketing with data-driven technologies. Digital technologies allow marketers to move from intuition and traditional research-based campaigns to technology-based, targeted messages to specific consumers (Yasmeen, 2017). As marketers demand more data-driven precision targeting, digital advertising and marketing companies such as adtechs and martechs are filling the gap left by traditional advertising agencies (Green, 2016). Notably, how consumers find products and product information has also moved from television and other legacy media to Google and Amazon. A significant number of consumers now rely on Google and Amazon to find what to buy (Semuels, 2018) and even when consumers purchase products at offline retail stores, it is often after conducting product searches on Google and Amazon.

Most advertising faculty would not be familiar with the technological developments in digital advertising and marketing. Practically speaking, it is difficult to keep up with the technological developments when a faculty member's job is teaching and conducting research. Moreover, even when a professor is willing to learn new technological developments, the hands-on knowledge is not readily available or accessible. Most advertising faculty would also agree that the current advertising education does not adequately reflect the digitalization in the industry.

\section{Impact of Technologies on Creative Process}

Digital technologies have also disrupted the creative process. Many agencies now look for graduates with digital graphic skills instead of standard graphic software skills. These days, digital graphics knowledge and skills are increasingly included in the job descriptions for new hires. While some may argue that the creativity principles still remain the same, changes in creative execution and application have already impacted the creative process. For example, a 2018 industry survey showed that marketers believe that growth in digital has negatively affected the quality of creative, and the creative process should incorporate technologies such as AI to make digital ads more engaging (Sizmek Research, 2018). The same survey also showed that marketers perceive the creative input as important as the use of technology in digital campaigns, 
suggesting that technologies should be incorporated into the creative process to lead to successful campaigns.

The creative process cannot just rely on ideas from a creative director's desk anymore. The advertising industry is increasingly becoming automated and the creative era of intuition and experience has largely gone. It is critical that the creative process integrates technologies to move forward to benefit consumers and businesses (Dudkiewicz, 2018). Moreover, creative collaboration involving diverse technology expertise is becoming a normal creative process. This trend in creative will continue as creativity must keep incorporating fast-developing technologies.

While creativity is still an integral part of the advertising process, advertising education has been slow to adopt technologies in creative courses. In many cases, the depth and breadth of knowledge on technologies among students who want to enter into the creative sector can be far short of the level the industry demands.

\section{Bridging the Gap}

\section{The Disciplinary Issues}

While the field of advertising has already embraced and applied crossdisciplinary knowledge into practice, teaching knowledge crossing different disciplines is not an easy issue in academia. Developing cross-disciplinary curriculum requires time-consuming coordination as well as administrative approval from different departments and necessitates identifying professors who are able and willing to teach cross-disciplinary classes.

The first step to develop cross-disciplinary curriculum could be to reach a consensus on the need to develop such curriculum. Advertising educators can open a dialogue with closely related disciplines such as business, computer science, and creative arts to discuss and develop courses that reflect real-world changes. It is also important to note that the consensus should be made within the school or college by different fields such as advertising, public relations, journalism, and communication studies before opening up the dialogue with other disciplines. Given that academia tends to be highly territorial (Broyles \& Slater, 2014), developing cross-disciplinary courses will take time and resources. Despite the potential hurdles, it is critical and urgent to develop cross-disciplinary courses as a first step. Cross-disciplinary programs then may be developed depending after the success of such efforts.

\section{Pedagogical Strategies}

In keeping up with trends in the industry, developing a fully revamped curriculum that meets the needs of the industry may not be a reality in a short period 
of time. However, while curriculum-level discussions are needed, some pedagogical adaptation or revision on individual courses is possible:

- Co-teaching courses. A faculty and a professional can revise an existing course or develop a new course. The faculty can address conceptual knowledge while the professional can deliver hands-on skills.

- Online courses. A professional can teach an online course via video applications such as Hangouts, Skype, or ooVoo. Theory-based courses can be considered.

- Hybrid courses. Similar to co-teaching, courses can be developed where a professor on campus teaches a course with a professional, who will teach online via a video application.

- Internships. While students always want internships, in reality, internships are not always easily accessible. In particular, the number of internships at major agencies and organizations tends to be limited to a small number of students. Advertising education may allocate more resources to find internship positions, but the industry must also be open-minded and provide more opportunities for students.

- Field trips/visits. Sometimes, one visit to an agency or client can greatly help students understand what's going on in the real world. Listening and talking to industry professionals can also be a fresh opportunity for students to have a sense of the real world and understand how they must prepare to work in the fast-moving industry.

These pedagogical strategies are not new to academia or advertising education. However, these are some of the pedagogical strategies that advertising education may need to utilize more proactively and frequently, given that bringing in industry professionals as full-time faculty is often a challenge, especially for relatively smaller programs.

\section{Faculty Development}

One important factor in revising curriculum to address the challenges is faculty development. Much of the gap between academia and the industry is evident in the knowledge gap for faculty members. While the industry is fast developing, individual faculty members' efforts to educate themselves can be limited. Advertising education must offer more faculty development programs with the help of the industry. While there are some programs such as AAF Visiting Professor Program, the scope is often limited to a few faculty.

In addition, academic conferences can be venues for faculty to educate themselves. Workshop programs at conferences can more frequently invite industry professionals and leaders to explain real-world trends and provide discussion forums. 
Faculty development in unfamiliar areas requires time, financial resources, and, importantly, individual faculty members' commitment. Concerted efforts by the members of the advertising education community are needed.

\section{Calling for the Thought Leadership}

Advertising educators must understand the urgency of filling the gap between academia and the industry. The current advertising curriculum remains outdated and cannot reflect the changes in the real world. Advertising is a highly applied field and must maintain constant contact with the industry. Although individual faculty members may try to incorporate industry developments into advertising courses, such efforts could be a short-term solution without revising the advertising curriculum as a whole. Moreover, many advertising programs must follow the accreditation guidelines, suggested by the Accrediting Council on Education in Journalism and Mass Communications (ACEJMC). While it is still important for any advertising program to get accredited by the ACEJMC, the current accreditation guidelines (see ACEJMC, 2018) also have not been updated to reflect the changes in the real world.

It is clear that the current status of advertising education calls for thought leadership to initiate the curriculum revision across advertising programs. Although there have been some calls regarding the need for change in the advertising curriculum (e.g., Blakeman \& Taylor, 2017; Broyles \& Slater, 2014; Habib, 2015; Newell, Tavanapong, \& Berghefer, 2017; Uslay, 2018), such efforts have not materialized in a concerted manner. Advertising education is currently at a critical juncture where thought leaders must emerge and guide the direction. Thought leaders can open up a dialogue between academia and industry leaders and initiate changes in the advertising education. Without such concerted efforts, the gap between academia and the industry will keep widening and the industry will not expect academia to supply talents who can meet the challenges in the real world. I also urge the advertising industry to be more proactive and receptive to the needs of academia. After all, academia is workforce supplier the industry needs. Finally, the gap between academia and the industry also exists in research. Given that teaching and research should go hand in hand, thought leaders can also open up a dialogue with industry leaders to understand their research needs.

\section{Declaration of Conflicting Interests}

The author declared no potential conflicts of interest with respect to the research, authorship, and/or publication of this article.

\section{Funding}

The author received no financial support for the research, authorship, and/or publication of this article. 


\section{References}

ACEJMC. (2018). Journalism and mass communication accreditation. ACEJMC. Retrieved from http://www.acejmc.org/wp-content/uploads/2018/09/2018-19ACEJMC-Booklet.pdf

Anonymous. (2018). Improving strategic execution with machine learning. MIT Sloan Management Review, 60, 2-7.

Bennett, B. (2018, April 5). Oath: Household addressable is a huge opportunity for agencies and advertisers. The Drum. Retrieved from https://www.thedrum.com/ news/2018/04/05/oath-household-addressable-huge-opportunity-agencies-andadvertisers

Bennin, K., \& Kapoor, N. (2017). Agency of the future: Next-generation operating models for marketing agencies. $P w C$. Retrieved from https://www.strategyand.pwc. com/report/agency-of-the-future

Blakeman, R., \& Taylor, M. (2017). Technology in the idea generation process: Voices from agency. Journal of Advertising Education, 21, 6-12.

Broyles, S., \& Slater, J. (2014). Big thinking about teaching advertising. Journal of Advertising Education, 18, 46-50.

Bruell, A. (2015, May 28). Programmatic TV to account for $\$ 10$ billion of TV budgets by 2019. Advertising Age. Retrieved from https://adage.com/article/agency-news/pro grammatic-tv-climb-10-billion-global-tv-budgets-2019/298786/

Bruell, A. (2018, August 27). In-house agencies on rise as advertisers seek services to home. The Wall Street Journal. Retrieved from https://www.wsj.com/articles/inhouse-agencies-on-rise-as-advertisers-seek-services-closer-to-home-1535367601

Burns, W. (2018, September 12). As in-house agencies become the norm, the opportunities for outside agencies evolve. Fortune. Retrieved from https://www.forbes.com/ sites/willburns/2018/09/12/as-in-house-agencies-become-the-norm-the-opportunitiesfor-outside-agencies-evolve/\#295e826f661c

Dudkiewicz, G. (2018, May 2). How the crossroads of creativity and big data will impact the industry. Adweek. Retrieved from https://www.adweek.com/digital/how-the-cross roads-of-creativity-and-big-data-will-impact-the-industry/

Green, J. (2016). Why agencies and marketers need to think and act like data companies. Martech. Retrieved from https://martechtoday.com/think-act-like-data-compa ny-172598

Habib, S. (2015). Teaching approaches in advertising: Creativity and technology. Journal of Advertising Education, 19, 17-25.

Newell, J., Tavanapong, W., \& Berghefer, S. (2017). Teaching ad tech: Assessing collaborative teaching in an advertising, computer science and design course. Journal of Advertising Education, 21, 45-53.

Rubel, S. (2016). Widening divide between agencies and clients could end badly for some agencies. Advertising Age. Retrieved from https://adage.com/article/steve-rubel/widen ing-divide-agencies-clients-end-badly-agencies/303319/

Schultz, B. (n.d.). The race is on! How IBM, Accenture, PwC and Deloitte are shaking up the marketing industry. Advertising Age. Retrieved from https://adage.com/article/ news/consultancies-rising/308845/

Semuels, A. (2018). The Amazon selling machine. The Atlantic. Retrieved from https:// www.theatlantic.com/technology/archive/2018/10/amazon-selling-machine/574045/ 
Silk, A., \& Stiglin, M. (2015). Build it, buy it or both? Rethinking the sourcing of advertising services. Harvard Business School Research Paper Series \# 15-093. Retrieved from https://www.hbs.edu/faculty/Publication\%20Files/15-093_38d66c04-fc7e-472fa42c-a860b60726c6.pdf

Sizmek Research. (2018). An insider's look at media, brand safety, and partnerships. Sizmek Research. Retrieved from https://info.sizmek.com/rs/303-WWQ-966/images/ Sizmek_Marketers_Survey_2018_Media.pdf

Slefo, G. (2017). Desktop and mobile ad revenue surpasses TV for the first time. Ad Age. Retrieved from https://adage.com/article/digital/digital-ad-revenue-surpasses-tv-desk top-iab/308808/

Soper, S. (2018). Amazon increases ad market share at expense of Google, Facebook. Bloomberg. Retrieved from https://www.bloomberg.com/news/articles/2018-09-19/ amazon-increases-ad-market-share-at-expense-of-google-facebook

Stanol, T. (2018, January 19). The case of the curious octopus: The evolution of the account manager. Advertising Age. Retrieved from https://adage.com/article/cmostrategy/evolution-account-management-function/311983/

Stephen, A. T. (2017). Here comes the hyper-connected augmented consumer. Gfk Marketing Intelligence Review, 9, 10-18.

Stewart, R. (2018). Marc Pritchard says $\mathrm{P} \& \mathrm{G}$ will soon have slashed "wasted" digital media spend by $50 \%$. The Drum. Retrieved from https://www.thedrum.com/news/ 2018/03/06/marc-pritchard-says-pg-will-soon-have-slashed-wasted-digital-mediaspend-50

Thompson, D. (2018, February 7). Where did all the advertising jobs go? The Atlantic. Retrieved from https://www.theatlantic.com/business/archive/2018/02/advertisingjobs-programmatic-tech/552629/

Uslay, C. (2018). Is advertising stuck in the middle? A commentary. Journal of Advertising Education, 22, 147-151.

Yasmeen, A. (2017). Recreating intimacy with connected consumers. Marketing Intelligence Review, 9, 49-54. 